\title{
sciendo
}

\author{
Current Issues in Pharmacy and Medical Sciences \\ Formerly ANNALES UNIVERSITATIS MARIAE CURIE-SKIODOWSKA, SECTIO DDD, PHARMACIA \\ journal homepage: http://www.curipms.umlub.pl/
}

\section{Effect of famotidine in combination with antiepileptic drugs on locomotor activity in mice}

\author{
Mariusz J. Swiader ${ }^{1 \star(0)}$, Katarzyna Swiader ${ }^{2}$, Izabela Zakrocka ${ }^{3}$, Darin MuniR ${ }^{1}$
}

\author{
${ }^{1}$ Department of Experimental and Clinical Pharmacology, Medical University, 20-090 Lublin, Jaczewskiego 8B \\ ${ }^{2}$ Department of Applied Pharmacy, Medical University, 20-093 Lublin, Chodźki 4A \\ ${ }^{3}$ Department of Nephrology, Medical University, 20-090 Lublin, Jaczewskiego 8
}

\begin{tabular}{l}
\hline ARTICLE INFO \\
\hline Received 04 September 2018 \\
Accepted 22 November 2018 \\
\hline Keywords: \\
exploratory locomotor activity, \\
spontaneous locomotor \\
activity, \\
antiepileptic drugs, \\
famotidine, \\
safety profile.
\end{tabular}

\begin{abstract}
Histamine type 2 receptor antagonists are one of the most commonly used agents to treat peptic ulcer disease. Since patients with epilepsy may have many comorbidities, the aim of this study was to investigate the influence of one of the strongest second generation histamine type 2 receptor antagonist, famotidine, on the exploratory and spontaneous activity in mice after 1 or 7 days treatment. Additionally, the interaction between famotidine and antiepileptics: carbamazepine, phenytoin, phenobarbital or valproate and their effect on animals activity was also evaluated. Locomotor activity was monitored electronically using a Digiscan analyzer in relation to ambulatory and rearing activities, as well as total distance travelled by animals during 15 minute periods. Results of our study indicate that famotidine administered alone did not modulate three variables of exploratory motor activity (horizontal activity, total distance and vertical activity) in mice. On the other hand, famotidine co-administered with valproate (1 day) or phenobarbital ( 1 day or 7 days) worsened vertical activity in mice in exploratory time. Similarly, impairment in horizontal activity in mice was observed when famotidine was given with phenobarbital (1 or 7 days). An increase in total distance in mice after famotidine alone or in combination with tested antiepileptic drugs was also shown. Moreover, famotidine alone or together with antiepileptic agents significantly impaired spontaneous locomotor activity in mice. The presented results show that famotidine administration to patients with epilepsy should be considered as potentially hazardous.
\end{abstract}

\section{INTRODUCTION}

Histamine has been reported as being the neurotransmitter in the central nervous system responsible for feeding, locomotor behaviors or consciousness regulation [1]. However, the role of histamine in seizures pathogenesis remains elusive. In most available studies, histamine's deficiency within the brain is suggested to be crucial in evoking seizure attacks.

Some researchers claim that histamine type $1(\mathrm{H} 1)$ receptor antagonists, a popular group of anti-allergic agents, may evoke convulsions in healthy children [2] or adults with epilepsy [3]. Additionally, Gerald and Richter observed that antihistamine agents increase clonic seizures susceptibility in mice [4]. What is more, Tuomisto and Tacke suggested that histamine may inhibit maximal electroshock seizures (MES) in mice [5]. Also Scherkl et al. reported that L-histidine, a precursor of histamine, increased pentetrazole-induced

\footnotetext{
^ Corresponding author

e-mail: mariusz.swiader@umlub.pl
}

seizure threshold in mice [6]. Centrally acting H1 receptor antagonists (i.e. diphenhydramine, antazoline or pyrilamine) were presented to potentiate electroconvulsions $[7,8]$ or chemoconvulsions [9].

Since the amount of patients with concomitant disorders is rapidly growing, and famotidine, a histamine type $2(\mathrm{H} 2)$ receptor antagonist, is one of the most efficacious drugs in peptic ulcer disease treatment, the goal of our study was to evaluate the influence of famotidine after 1 or 7 days administration on locomotor activity in mice, alone or in combination with conventional antiepileptic drugs: carbamazepine (CBZ), phenytoin (PHT), phenobarbital (PB) and valproate (VPA). Hence, CBZ, PHT, PB and VPA were administered at doses equal to their median effective dose (ED50) against maximal electroshock in mice, while famotidine was given at the dose of $5 \mathrm{mg} / \mathrm{kg}$, which affected the electroconvulsive threshold [10]. 


\section{MATERIALS AND METHODS}

\section{Animals}

Adult male Swiss albino mice (weight 22-26 g) were purchased from a licensed breeder (Dr T. Gorzkowska, Warsaw, Poland). The animals were kept in colony cages in standard laboratory conditions (temperature $23 \pm 2^{\circ} \mathrm{C}$, natural lightdark cycle) with food (Murigran pellets, Bacutil, Motycz, Poland) and tap water available ad libitum. After 7 days of adaptation, the animals were randomly assigned into experimental groups consisting of 12 animals - the amount needed to achieve reliable results. Experiments were performed between 10 a.m. to 2 p.m. Each animal was used only once. All experimental procedures were approved by the I Local Ethics Committee for Animal Experiments in Lublin, Poland.

\section{Substances}

Famotidine (Polfa Warsaw, Poland) and antiepileptic drugs: valproate magnesium (Dipromal, Polfa Rzeszow, Poland), carbamazepine (Amizepin, Polfa Warsaw, Poland), phenytoin (Polfa Warsaw, Poland) and phenobarbital (Polfa Warsaw, Poland) were used in the presented study. Valproate and phenobarbital were dissolved in distilled water, whereas famotidine, phenytoin and carbamazepine were suspended in 1\% Tween 80 solution (Sigma St. Louis, MO, USA). All drugs were given intraperitoneally (i.p.) in a volume of $0.1 \mathrm{ml} / \mathrm{g}$ body mass, 30 minutes before the locomotor tests.

\section{Locomotor activity examination}

\section{Equipment}

Locomotor activity was analyzed with the use of an Digiscan Animal Activity Monitor System (Omnitech Electronics, Columbus, OH, USA). Each monitor contained a plexiglass open field box $(41 \times 41 \times 32 \mathrm{~cm})$ with a grid of infrared beams mounted horizontally every $2.5 \mathrm{~cm}$ and vertically every $4.5 \mathrm{~cm}$. Photocells put on the wall opposite to each photo-beam were activated when the animal interrupted a beam. Each box was divided into four quadrants $(20 \times 20 \times 32 \mathrm{~cm})$ by acrylic cross-pieces. For experimental purposes, mice were placed in the opposite quadrant of each unit (i.e. two mice per box). The photocells from each activity box were then connected to the Digiscan analyzer, which transmitted beam breaks (activity data) to a computer. During our study, the pattern of beam interruptions was recorded and analyzed by an IBM-PC compatible computer. The monitoring system recorded interruptions from each infrared beam at $100 \mathrm{~Hz}$ frequency. Any beam interruption was reported as an activity score. Concomitant interruption of two or more beams separated by at least one second was recorded as a movement score.

The Digiscan Analyzer collected data for each animal and cumulated this data into two 15 minutes time bins for each test session. The system-differentiated behavioral variables recorded for each test session were: for horizontal activity - total number of beam interruptions for the lower set of infrared beams - herein, we assessed movement time the amount of time the animal was in motion during a given time sample; for total distance - the horizontal distance travelled by an animal in a given sample period; vertical activity - total number of beam interruptions for the upper set of bea ms - herein, we assessed the number of separate vertical movements (rearing) separated by at least $1 \mathrm{sec}$. Data were saved every 15 minutes into computer.

\section{Procedures}

The day before the tests, the animals were habituated to the experimental procedures. Prior to the test, the animals were deprived of food for 24 hours. On the subsequent day, the mice were tested in the same conditions. Antiepileptic drugs were administered at doses equal to their $\mathrm{ED}_{50}$ values and at times scheduled for the electroconvulsive test, according to Świąder et al. [7]. Each mouse immediately after drug administration, was placed inside the activity chamber. Tests were performed twice and lasted 15 minutes each. The first record was categorized as exploratory activity test, whereas the second was defined as spontaneous mice activity.

\section{Drugs administration}

The animals received a single dose of famotidine (1 or 7 days) and one of the tested antiepileptic drugs at the time prior to tests described above. Antiepileptic agents were examined at the time of their maximal anticonvulsant activity according to previous studies [8,9], whereas famotidine's maximal activity time was as determined as per the method of Świąder et al. [10].

\section{Study protocol}

The animals received a single dose of famotidine as an intraperitoneal injection and one of the tested antiepileptic agents at the time prior to tests described above. Antiepileptic drugs were analyzed at the time of their peak anticonvulsant activity according to previously published studies. Adversely, famotidine's time of maximal activity was determined experimentally [10].

\section{Statistical analysis}

Results of locomotor activity measurement were statistically analyzed with the use of Kruskal-Wallis test (nonparametric ANOVA test) followed by Dunn's test.

\section{RESULTS}

\section{Effect of famotidine alone or in combination with antiepileptic drugs on exploratory locomotor activity in mice}

Famotidine administered alone (at the dose $5 \mathrm{mg} / \mathrm{kg}$ ) for 1 or 7 days did not change mice motor activity, i.e. horizontal activity, total distance or vertical activity. Interestingly, famotidine significantly decreased mice vertical activity when co-administered for 1 day with VPA or PB (Table 1). Similarly, famotidine, after 7 days of administration, lowered vertical activity in mice when given together with PB (Table 2). What is more, famotidine $(5 \mathrm{mg} / \mathrm{kg})$ significantly impaired the horizontal activity of mice receiving PB for 1 day (dose $18.8 \mathrm{mg} / \mathrm{kg}$ ) or for 7 days (at the dose $18.1 \mathrm{mg} / \mathrm{kg}$ ). However, the animals demonstrated an increase in total distance when treated with a single dose of VPA (249 mg/kg), PB (18.8 mg/kg and $21.8 \mathrm{mg} / \mathrm{kg}$ dose) 
and CBZ (11.2 mg/kg) or famotidine in combination with PB or CBZ (Table 1). After 7 days of experiment, an increase in total distance in mice was observed after administration of VPA, PB and CBZ or co-administration of famotidine and VPA, CBZ, PB and PHT (Table 2).

\section{Effect of famotidine alone or in combination with antiepileptic drugs on spontaneous locomotor activity in mice}

Treatment with famotidine $(5 \mathrm{mg} / \mathrm{kg})$, PB or PHT alone significantly impaired vertical activity in mice after single

Table 1. Effect of famotidine (1-day treatment) on exploratory locomotor activity in mice

\begin{tabular}{|c|c|c|c|}
\hline \multirow{2}{*}{ Drug $[\mathrm{mg} / \mathrm{kg}]$} & \multicolumn{2}{|c|}{ Horizontal activity } & \multirow{2}{*}{\begin{tabular}{|c} 
Vertical activity \\
Movement
\end{tabular}} \\
\hline & Movement & Total distance & \\
\hline Vehicle & $1972 \pm 175$ & $764 \pm 76$ & $293 \pm 42$ \\
\hline Famotidine [5] & $1895 \pm 215$ & $1027 \pm 163$ & $361 \pm 57$ \\
\hline VPA [249] & $1724 \pm 196$ & $1304 \pm 136 * *$ & $164 \pm 21 *$ \\
\hline VPA [190] & $1818 \pm 277$ & $1279 \pm 206$ & $295 \pm 53$ \\
\hline VPA [190] + Famotidine [5] & $1768 \pm 364$ & $1251 \pm 362$ & $163 \pm 34 *$ \\
\hline PB [21.8] & $3150 \pm 487$ & $2440 \pm 386 * *$ & $575 \pm 134$ \\
\hline PB [18.8] & $2941 \pm 356$ & $2147 \pm 347 * *$ & $602 \pm 46 * *$ \\
\hline PB [18.8] + Famotidine [5] & $2655 \pm 122 *$ & $1940 \pm 362 * *$ & $295 \pm 53 *$ \\
\hline PHT [9.1] & $1919 \pm 148$ & $1009 \pm 298$ & $456 \pm 82$ \\
\hline PHT [8.2] & $1628 \pm 176$ & $566 \pm 69$ & $208 \pm 36$ \\
\hline PHT [8.2] + Famotidine [5] & $1611 \pm 188$ & $660 \pm 75$ & $203 \pm 21$ \\
\hline CBZ [10.0] & $2410 \pm 324$ & $1244 \pm 236$ & $462 \pm 89$ \\
\hline CBZ [11.2] & $2413 \pm 252$ & $1345 \pm 241 * *$ & $394 \pm 50$ \\
\hline CBZ [11.2] + Famotidine [5] & $1981 \pm 152$ & $1022 \pm 298 *$ & $294 \pm 32$ \\
\hline
\end{tabular}

Table 2. Effect of famotidine (7 days treatment) on exploratory locomotor activity in mice

\begin{tabular}{|c|c|c|c|}
\hline \multirow{2}{*}{ Drug $[\mathrm{mg} / \mathrm{kg}]$} & \multicolumn{2}{|c|}{ Horizontal activity } & \multirow{2}{*}{$\begin{array}{c}\text { Vertical activity } \\
\text { Movement }\end{array}$} \\
\hline & Movement & Total distance & \\
\hline Vehicle & $1556 \pm 88$ & $667 \pm 28$ & $232 \pm 28$ \\
\hline Famotidine [5] & $1691 \pm 108$ & $805 \pm 53$ & $346 \pm 55$ \\
\hline VPA [232] & $1979 \pm 230$ & $1362 \pm 178 * *$ & $328 \pm 44$ \\
\hline VPA [233] & $1794 \pm 146$ & $1304 \pm 136 * *$ & $289 \pm 53$ \\
\hline VPA [233] + Famotidine [5] & $2005 \pm 314$ & $1476 \pm 279 * *$ & $183 \pm 32$ \\
\hline PB [21.8] & $3322 \pm 392 * *$ & $2477 \pm 205^{* *}$ & $573 \pm 97 * *$ \\
\hline PB [18.1] & $2879 \pm 320 * *$ & $1831 \pm 235^{* *}$ & $551 \pm 59 * *$ \\
\hline PB [18.1] + Famotidine [5] & $2625 \pm 111 * *$ & $1751 \pm 87 * *$ & $461 \pm 33 * *$ \\
\hline PHT [10.9] & $1756 \pm 97$ & $847 \pm 63$ & $440 \pm 70$ \\
\hline PHT [8.2] & $1774 \pm 188$ & $581 \pm 63$ & $239 \pm 30$ \\
\hline PHT [8.2] + Famotidine [5] & $1675 \pm 153$ & $628 \pm 50 *$ & $228 \pm 17$ \\
\hline CBZ [11.4] & $2243 \pm 307 * *$ & $1026 \pm 91 *$ & $471 \pm 66 * *$ \\
\hline CBZ [14.1] & $2100 \pm 130 *$ & $1343 \pm 141 * *$ & $362 \pm 31 *$ \\
\hline CBZ [14.1] + Famotidine [5] & $1690 \pm 134$ & $1104 \pm 70 * *$ & $302 \pm 35$ \\
\hline
\end{tabular}

${ }^{*} \mathrm{P}<0.05$ vs. vehicle, ${ }^{* *} \mathrm{P}<0.01$ vs. vehicle

Valproate (VPA), phenobarbital (PB), phenytoin (PHT) and carbamazepine (CBZ) were given i.p. 30 min before the test. Famotidine was given i.p. 30 min before the test. Data are expressed as means $\pm S D, n=12$, KruskalWallis with Dunn's post-hoc test. administration (Table 3). Similar results were observed when famotidine was co-administered with PHT or VPA. Moreover, single famotidine administration was shown to increase total distance, however, a combined treatment with PB caused the opposite result (Table 3). Finally, phenytoin alone or combined treatment with famotidine and PHT or PB significantly decreased mice movement after single administration (Table 3).

After 7 days of experiment, famotidine, VPA, PHT and $\mathrm{CBZ}$ injected alone affected mice vertical activity as well (Table 4). When famotidine was administered

Table 3. Effect of famotidine (1-day treatment) on spontaneous locomotor activity in mice

\begin{tabular}{|c|c|c|c|}
\hline \multirow{2}{*}{ Drug $[\mathrm{mg} / \mathrm{kg}]$} & \multicolumn{2}{|c|}{ Horizontal activity } & Vertical activity \\
\hline & Movement & Total distance & Movement \\
\hline Vehicle & $1545 \pm 185$ & $528 \pm 130$ & $261 \pm 36$ \\
\hline Famotidine [5] & $1966 \pm 284$ & $1193 \pm 297 *$ & $832 \pm 49 * *$ \\
\hline VPA [249] & $1478 \pm 208$ & $754 \pm 93$ & $197 \pm 30$ \\
\hline VPA [190] & $1478 \pm 122$ & $640 \pm 74$ & $285 \pm 41$ \\
\hline VPA [190] + Famotidine [5] & $1177 \pm 87$ & $557 \pm 62$ & $155 \pm 19 \#$ \\
\hline PB [21.8] & $1724 \pm 360$ & $1094 \pm 358$ & $439 \pm 73 *$ \\
\hline PB [18.8] & $1772 \pm 159$ & $827 \pm 163$ & $253 \pm 43$ \\
\hline PB [18.8] + Famotidine [5] & $1343 \pm 73 \#$ & $395 \pm 93 \#$ & $174 \pm 21$ \\
\hline PHT [9.1] & $1717 \pm 270$ & $873 \pm 347$ & $342 \pm 50$ \\
\hline $\mathrm{PHT}[8.2]$ & $929 \pm 93 *$ & $224 \pm 41$ & $120 \pm 30 *$ \\
\hline PHT [8.2] + Famotidine [5] & $900 \pm 103 *$ & $269 \pm 45$ & $124 \pm 10 *$ \\
\hline CBZ [10.0] & $1712 \pm 213$ & $628 \pm 101$ & $238 \pm 40$ \\
\hline CBZ [11.2] & $1671 \pm 284$ & $565 \pm 60$ & $206 \pm 32$ \\
\hline CBZ [11.2] + Famotidine [5] & $1078 \pm 155$ & $423 \pm 45$ & $194 \pm 34$ \\
\hline
\end{tabular}

$* \mathrm{P}<0.05$ vs. vehicle, $* * \mathrm{P}<0.01$ vs. vehicle, $\# \mathrm{P}<0.05$ vs. drug

Valproate (VPA), phenobarbital (PB), phenytoin (PHT) and carbamazepine (CBZ) were given i.p. 30 min before the test. Famotidine in a single dose was given i.p. 30 min before the test. Data are expressed as means \pm SD, $n=12$, Kruskal-Wallis with Dunn's post-hoc test

Table 4. Effect of famotidine (7 days treatment) on spontaneous locomotor activity in mice

\begin{tabular}{|l|c|c|c|}
\hline \multirow{2}{*}{ Drug [mg/kg] } & \multicolumn{2}{c|}{ Horizontal activity } & Vertical activity \\
\cline { 2 - 4 } & Movement & Total distance & Movement \\
\hline Vehicle & $1683 \pm 127$ & $585 \pm 105$ & $294 \pm 16$ \\
\hline Famotidine [5] & $2002 \pm 269$ & $1157 \pm 160 * *$ & $845 \pm 16 * *$ \\
\hline VPA [232] & $1478 \pm 121$ & $607 \pm 46$ & $280 \pm 23$ \\
\hline VPA [233] & $1538 \pm 186$ & $731 \pm 58$ & $182 \pm 19 * *$ \\
\hline VPA [233] + Famotidine [5] & $1166 \pm 94 * \# \#$ & $541 \pm 55 \# \#$ & $177 \pm 20 * * \#$ \\
\hline PB [21.8] & $1464 \pm 219$ & $1201 \pm 218 *$ & $387 \pm 68$ \\
\hline PB [18.1] & $1603 \pm 131$ & $719 \pm 107$ & $268 \pm 40$ \\
\hline PB [18.1] + Famotidine [5] & $1290 \pm 57 *$ & $380 \pm 92 \#$ & $191 \pm 15 * *$ \\
\hline PHT [10.9] & $1126 \pm 125 *$ & $603 \pm 94$ & $294 \pm 43$ \\
\hline PHT [8.2] & $973 \pm 85 * *$ & $240 \pm 36 *$ & $137 \pm 27 * *$ \\
\hline PHT [8.2] + Famotidine [5] & $957 \pm 92 * *$ & $282 \pm 38$ & $119 \pm 9 * *$ \\
\hline CBZ [11.4] & $1556 \pm 203$ & $543 \pm 57$ & $189 \pm 20$ \\
\hline CBZ [14.1] & $1639 \pm 173$ & $593 \pm 86$ & $189 \pm 20 * *$ \\
\hline CBZ [14.1] + Famotidine [5] & $1083 \pm 124 * *$ & $406 \pm 42$ & $178 \pm 21 * *$ \\
\hline
\end{tabular}

${ }^{*} \mathrm{P}<0.05$ vs. vehicle, ${ }^{* *} \mathrm{P}<0.01$ vs. vehicle, ${ }^{*} \mathrm{P}<0.05$ vs. drug, ${ }^{* *} \mathrm{P}<0.01$ vs. drug Valproate (VPA), phenobarbital (PB), phenytoin (PHT) and carbamazepine (CBZ) were given i.p. 30 min before the test. Famotidine was given i.p. 30 min before the test. Data are expressed as means $\pm S D, n=12$, KruskalWallis with Dunn's post-hoc test 
in combination with every tested antiepileptic drug, vertical activity was significantly decreased (Table 4).

Total distance in mice treated with famotidine or PHT for 7 days was significantly increased compared to control group (Table 4), however, the combination of famotidine and VPA or PB brought about the opposite effect. Additionally, co-administration of famotidine with every analyzed antiepileptic drug significantly impaired movement after 7 days of treatment (Table 4).

\section{DISCUSSION}

The influence of histamine receptor antagonists on seizure threshold in animals and humans has recently gained attention. In a previously published study, it was reported that famotidine, a $\mathrm{H} 2$ receptor antagonist, at the dose of $10 \mathrm{mg} / \mathrm{kg}$ raised the threshold for electroconvulsions [10]. Given for 1 or 7 days at a $5 \mathrm{mg} / \mathrm{kg}$ dose, famotidine also increased the anticonvulsant properties of VPA (lower VPA's $\mathrm{ED}_{50}$ ) against MES-induced seizures [10]. Moreover, after 7 days of administration, famotidine $(5 \mathrm{mg} / \mathrm{kg})$ significantly improved the anticonvulsant effect of PHT against MES. Famotidine, given for 7 days also did not change the free plasma and brain levels of the tested antiepileptic drugs [10] thus, pharmacokinetic interactions are less possible. Interestingly, single dose administration of famotidine $(5 \mathrm{mg} / \mathrm{kg})$ elevated the brain concentration of VPA [10]. What is more, it was observed that famotidine given together with PHT and CBZ impaired mice motor coordination, without affecting long-term memory [10]. Adversely, famotidine given up to $10 \mathrm{mg} / \mathrm{kg}$ did not change the proconvulsant effect of aminophylline and did not modify its total brain and plasma level [9].

The presented results indicate that famotidine may lead to horizontal or vertical movement impairment in mice receiving VPA or PB. What is more, famotidine alone and in combination with the tested antiepileptics increased total distance in mice. Spontaneous activity in mice was, as well, disturbed after famotidine given alone or together with the examined antiepileptic drugs.

The achieved effects can be observed after peripheral administration. Despite poor blood-barrier penetration among $\mathrm{H} 2$ receptor antagonists, famotidine was reported to reach the central nervous system and exert neuropsychiatric effects (i.e. improving the course of schizophrenia) [11]. On the other hand, delirium after starting famotidine administration was presented as well, by Yuan et al. [12].
In conclusion, a representative of the $\mathrm{H}_{2}$ receptor antagonists, famotidine administration should be considered with great caution in patients with epilepsy. However, concomitant famotidine and antiepileptic drugs treatment may be important from the clinical point of view and needs further exploration.

\section{ACKNOWLEDGEMENTS}

This study was supported by the grant No P05A 04418 from the State Committee for Scientific Research, Warsaw, Poland.

\section{ORCID iDs}

Mariusz Świąder (Dhttps://orcid.org/0000-0001-8093-1654

\section{REFERENCES}

1. Wada H, Inagaki N, Itowi N, Yamatodani A. Histaminergic neuron system in the brain: distribution and possible functions. Brain Res Bull. 1991;27(3-4):367-70.

2. Wyngaarden JB, Seevers MH. The toxic effects of antihistaminic drugs. J Am Med Assoc. 1951;145(5):277-82.

3. Churchill JA, Gammon GD. The effect of antihistaminic drugs on convulsive seizures. J Am Med Assoc. 1949;141(1):18-21.

4. Gerald MC, Richter NA. Studies on the effects of histaminergic agents on seizure susceptibility in mice. Psychopharmacologia. 1976; 46(3):277-82

5. Tuomisto L, Tacke U. Is histamine an anticonvulsive inhibitory transmitter? Neuropharmacology. 1986;25(8):955-8.

6. Scherkl R, Hashem A, Frey HH. Histamine in brain-its role in regulation of seizure susceptibility. Epilepsy Res. 1991;10(2-3):111-8.

7. Świąder M, Kalisz A, Porebiak J, Kleinrok Z, Czuczwar SJ. Influence of antazoline on the anticonvulsant activity of conventional antiepileptic drugs against maximal electroshock-induced seizures in mice. Pol J Pharmacol. 1999;51(1):104.

8. Świąder M, Chwalczuk K, Wielosz M, Czuczwar SJ. Influence of chronic treatment with $\mathrm{H} 1$ receptor antagonists on the anticonvulsant activity of antiepileptic drugs. Pol J Pharmacol. 2001;53(1):93-6.

9. Świąder MJ, Łuszczki JJ, Wielosz M, Czuczwar SJ. Effect of histamine receptor antagonists on aminophylline-induced seizures and lethality in mice. Pharmacol Rep. 2005;57(4):531-5.

10. Świąder MJ, Czuczwar SJ. Interaction of famotidine, an $\mathrm{H} 2$ histamine receptor antagonist, with conventional antiepileptic drugs in mice. Pharmacol Rep. 2014;66(3):485-91.

11. Oyewumi LK, Vollick D, Merskey H, Plumb C. Famotidine as an adjunct treatment of resistant schizophrenia. J Psychiatry Neurosci. 1994;19(2):145-50.

12. Yuan RY, Kao CR, Sheu JJ, Chen CH, Ho CS. Delirium following a switch from cimetidine to famotidine. Ann Pharmacother. 2001; 35(9):1045-8 